\title{
Highlighting the Relevance of Mathematics to Secondary School Students - Why and How
}

\author{
Olivia Fitzmaurice ${ }^{1 *}$, Niamh O’Meara ${ }^{1}$, Patrick Johnson ${ }^{1}$ \\ ${ }^{1}$ EPISTEM, National Centre for STEM Education, School of Education, University of Limerick, IRELAND
}

*Corresponding Author: olivia.fitzmaurice@ul.ie

Citation: Fitzmaurice, O., O’Meara, N. and Johnson, P. (2021). Highlighting the Relevance of Mathematics to Secondary School Students - Why and How. European Journal of STEM Education, 6(1), 07. https://doi.org/10.20897/ejsteme/10895

Published: May 9, 2021

\begin{abstract}
A lack of knowledge and appreciation of the prominence of mathematics in different careers can have a negative impact on a student's engagement with the subject. A perceived lack of relevance can result in disinterest, and even disengagement with mathematics entirely. This can lead to more serious consequences for the economy of a country who requires a consistent flow of well-educated science, technology, and mathematics graduates to ensure economic and social development. Research shows that the textbook is the most commonly used resource in Irish classrooms. Textbooks impact significantly on teaching and learning as they dictate what will be taught, in what order, and how. For this reason, this research commenced with an analysis of local textbooks to evaluate how well they highlight the relevance of mathematics within careers. This textbook analysis, in conjunction with interviews conducted with secondary school mathematics teachers, indicate a distinct lack of resources and support for teachers who want to highlight the relevance of mathematics within a range of careers as a means of enhancing student motivation and engagement with the subject. These findings motivated the conception of a pilot study designed to support secondary school mathematics teachers to fill this gap in teaching resources.
\end{abstract}

Keywords: mathematics education, STEM education, relevance of mathematics, careers education

\section{INTRODUCTION}

STEM is the acronym for the fields of science, technology, engineering, and mathematics. Policy makers and stakeholders understand that a consistent supply of well-educated STEM graduates is crucial to the success of a competitive economy and the health and welfare of all its constituents (Mujtaba, Reiss and Hodgson, 2014; Mujtaba, Reiss, Rodd and Simon, 2015; Reiss, 2004; Reiss and Mujtaba, 2017; Tripney et al., 2010). However, there is a concern in the UK and Ireland that the current number of STEM graduates is insufficient (Expert Group on Future Skills Needs, 2008; Reiss and Mujtaba, 2017) and, if not reversed, will have long-term devastating effects on the economy (Bennett, Braund and Sharpe, 2014).

Mathematics is recognised as the language that underpins all other STEM disciplines as well as the medical and social sciences, yet is accepted as a formidable discipline in its own right (Smith, 2004). The need for a country to increase the mathematical skills and proficiency of its students has been highlighted by many stakeholders (Hoyles, Wolf, Molyneux-Hodgson and Kent, 2002; Mujtaba et al., 2014) as it is the medium through which problems are solved in most areas including the physical sciences, computer science, engineering and medicine (Sheldrake, Mujtaba and Reiss, 2015). Mathematics widens the range of options available to young people, as it is a prerequisite for many university courses (Central Applications Office, 2020; Johnston, 1994). A school qualification in 
mathematics has been demonstrated to lead to more successful outcomes in relation to acceptance into choice of university, future career and increased salary (Mujtaba et al., 2014).

Mathematics pervades most occupations. It is often the case that mathematics exists implicitly in a variety of jobs and tasks, which are not explicitly mathematical (Hoyles et al., 2002; Keogh, Maguire and O'Donoghue, 2018). In 2002, an analysis of workplace mathematics conducted by Hoyles et al. (2002) found that the majority of employees surveyed, regardless of the level at which they were employed, required some level of mathematical proficiency. Today not only is mathematical proficiency still a prerequisite in most jobs (Hoyles et al., 2002; Keogh et al., 2018), there exists a strong relationship between the mathematical proficiency of many professionals and their competence in their field of expertise (Flegg, Mallet and Lupton, 2012). The mathematics skillsets demanded by employers are constantly changing and, frequently, employees are required to be proficient in a range of mathematics skills and competencies that would not have been needed by their predecessors. For this reason, mathematics education provision for young people needs to be appropriate and adapted regularly (Hoyles et al., 2002). It should bolster a person by providing them with a skillset that will be vital regardless of the profession they choose (Smith, 2004). However, there exists a distinct mismatch between skills acquired at school and those desired/required by the workplace (Smith, 2004; Tripney et al., 2010). In 2004, the Smith Report, a large-scale inquiry conducted into the state of mathematics education in the UK, stated that the curriculum was not addressing the needs of learners, employers, or higher education institutions. This has contributed to participation rates in STEM subjects, at the upper end of secondary school education, particularly at an advanced level, being cause for concern in the UK, Ireland and Australia for a number of years (Archer, Osborne, De Witt, Willis and Wong, 2013; Johnston, 1994; Mujtaba, Sheldrake, Reiss and Simon, 2018). To address this issue, this paper outlines a novel approach to support teachers in their attempts to engage secondary school students in STEM subjects by informing them about the importance and relevance of mathematics within a range of careers.

\section{STUDENTS' PERCEPTIONS OF THE RELEVANCE AND UTILITY OF MATHEMATICS}

The message that mathematics is useful and important is either not being heard or not believed by students (Brown, Brown and Bibby, 2008), with the result that too many young people make subject choices, when permitted to do so, that they later regret (Reiss and Mujtaba, 2017). High levels of disaffection with mathematics are common themes throughout the literature (Brown et al., 2008; Mujtaba et al., 2015; Reiss and Mujtaba, 2017). A study conducted by Hodgen and Askew (2007) of secondary school students demonstrated that mathematics is viewed less favourably than other subjects. Many students, both low and high attaining, perceive mathematics to be dull, boring, and irrelevant (Matthews and Pepper, 2006; Mujtaba et al., 2014; Smith, 2004). It is seen as too traditional and less useful than other subjects (Tebbutt, 1993). The Smith report (2004) indicated that GCSE (the General Certificate of Secondary Education, typically taken at the age of 15/16) mathematics appeared boring and irrelevant to students' lives and was not conducive to the further studying of mathematics. Similarly, Nardi and Steward's (2003) research concluded that for most students, mathematics was tedious and an "irrelevant body of isolated non-transferable skills, the learning of which offers little opportunity for activity" (Nardi and Steward, 2003, p. 361).

Many students therefore have the opinion that mathematics is neither needed nor useful to them, in school or in their future studies and careers (Brown et al., 2008). It is viewed as an isolated school subject that lacks connections to life and other subject areas (Nardi and Steward, 2003). Even within the cohort of students who do enjoy and manage to succeed at mathematics, a prevalent belief still exists that mathematics will never be useful, at any stage of their lives (Matthews and Pepper, 2006; Nardi and Steward, 2003). Matthews and Pepper (2005) and Kyriacou and Goulding (2006) found that students failed to see the relevance of either the GCSE or A-level (Advanced Level qualifications are the UK subject-based qualification for students aged 16 and above, usually studied over the course of two years) mathematics they studied at school, or how they would be of value in their futures.

Seeing the relevance of school lessons for students is important both for intrinsic motivation (Mujtaba et al., 2014; Mujtaba et al., 2018) and extrinsic motivation i.e., a perception of utility in life or in future studies and/or career (Mujtaba et al., 2018). In fact, the utility of a subject/extrinsic motivation has been found to have a bigger influence on some subject choices than intrinsic motivation (Sheldrake et al., 2015). Brown et al. (2008) found that the perception of mathematics not being useful for future careers was the main reason offered by students for why they discontinued studying it after the GCSE.

Making education relevant to students' lives (current and future) should result in increased learning and engagement (Hulleman and Harackiewicz, 2009). Students enjoy a subject more when they perceive the content to be relevant (Smart and Rahman, 2008). Increased emphasis on relevance helps students to identify better with a range of careers and thus increases the chances of students opting for STEM subject/career choices when 
permitted to do so (Hulleman and Harackiewicz, 2009). One evidenced based approach to introducing relevance into the mathematics curriculum is called Realistic Mathematics Education and is outlined next.

\section{REALISTIC MATHEMATICS EDUCATION (RME)}

Realistic Mathematics Education (RME) is an approach to teaching and learning to counter the boredom and difficulties which tend to occur as a result of traditional, abstract mathematics learning that lacks context (Laurens, Batlolona, Batlolona and Leasa, 2017). It was derived from the research of Hans Freudenthal who believed that abstraction was a great weakness, rather than a strength of mainstream mathematics, because '...it is wasted on individuals who are not able to avail themselves of this flexibility' (Hans Freudenthal, 1968, p. 5). He wrote that mathematics is primarily a human activity and therefore reality should be embedded in mathematics education (Gravemeijer and Terwel, 2000). RME endorses the notion that reality is the source of mathematics, not just where it is applied/utilised (Treffers, 1993). Devrim and Uyangor (2006, p. 1952) state that

'These real situations can include contextual problems or mathematically authentic contexts for learners where they experience the problem presented as relevant and real. Learners therefore learn mathematics by mathematising subject matter from real contexts and from their own mathematical activity'.

Reality thus leads to mathematical models and from here one may progress to more abstract mathematics. This represents a move from what is termed horizontal to vertical mathematising. Freudenthal (1991, pp. 41-42) distinguished between horizontal and vertical mathematisation as follows:

'Horizontal mathematisation leads from the world of life to the world of symbols. In the world of life one lives, acts (and suffers); in the other one symbols are shaped, reshaped, and manipulated, mechanically, comprehendingly, reflectingly; this is vertical mathematisation. The world of life is what is experienced as reality (in the sense I used the word before), as is symbol world with regard to its abstraction'.

This distinction makes it possible to characterise different types of mathematics teaching and learning. Freudenthal (1991, p. 133) classified mathematics curricula into 4 categories: mechanistic, empiricist, structuralist and realistic. The 'mechanistic' approach encompasses neither vertical nor horizontal mathematising. A course of this nature would encourage mathematics being learned and applied to routine step-by-step problems and lacks any real life or realistic contexts. 'Empiricist' mathematics education endorses horizontal mathematisation but lacks any vertical mathematisation. Here students learn mathematics from the world as they know it, however they are not required to schematise this knowledge or progress beyond this. A 'structuralist' approach to mathematics education includes vertical mathematisation, in the absence of horizontal mathematisation, thereby not including any content relating to the real world 'Realistic' mathematics education comprises both types of mathematising as defined by Freudenthal. In a curriculum like this, mathematical tasks originate in real life settings which is the basis of horizontal mathematising - putting real life into mathematical form. Mathematical skills are then required to solve these problems, which embodies vertical mathematising (Gill, 2006). The literature supports the view that a realistic mathematics curriculum, which encompasses both vertical and horizontal mathematising should be available to all students studying mathematics (Gravemeijer and Terwel, 2000; Vos, 2020). It provides the framework for the intervention described in this research.

\section{CAREER GUIDANCE ACROSS STEM DISCIPLINES}

School factors that influence uptake of various subjects include career advice provided to students (Bennett et al., 2014). It is believed that schools have a responsibility to inform students of the range of further study and career options when they finish (Reiss and Mujtaba, 2017). However, there is concern about the quality of the provision of careers education, and STEM careers education in particular (Archer et al., 2013; Reiss and Mujtaba, 2017). In the UK, shifts in government policy and funding have resulted in careers education being unsatisfactory and not being given the priority it warrants (Reiss and Mujtaba, 2017). Similar reports emerged from Ireland in 2018, stating that careers guidance at school is under resourced and ineffective and therefore not meeting the needs of learners (Irish Business and Employers Confederation, 2018). Part of the reason for this ineffective delivery of STEM careers education/guidance, is that careers teachers rarely have a background in STEM and there is a danger that the education they provide about STEM subjects can be out of date or stereotyped (Reiss and Mujtaba, 2017). Bennett et al. (2014) found that schools where there were high levels of GCSE participation in science had careers advice actively facilitated by science teachers and staff. 
The need for the provision of better careers education has been highlighted in previous research (Bennett et al., 2014). Smith (2004) flagged a lack of useful careers advice in schools about mathematics and the study of mathematics and stated that it was an area that needed to be addressed as a high priority. Recent research papers state that it has not improved much in the decade since the Smith report. Archer et al. (2013) found that one quarter of secondary school students surveyed said that school did influence their choice of career but less than $0.5 \%$ were influenced in any way by the careers education provided in their school.

Opportunities for students to engage with the world of work, through the use of role models in the local community, i.e., STEM Ambassadors, is one vehicle for educating students on the possibilities the study of STEM disciplines can lead to (Bennett et al., 2014). It has been shown that the introduction of STEM Ambassadors at school has benefits for all: students, teachers and schools (Reiss and Mujtaba, 2017). Bennett et al. (2014) reported on a project in the USA which was designed to raise interest in STEM subjects by assigning to each female student a STEM mentor. The project resulted in a significant number of girls planning to pursue a career in mathematics (Bennett et al., 2014). In science the use of ambassadors facilitating career talks and giving advice and demonstrations within schools has been shown to result in increased levels of interest in the subject, and heightened ambitions towards careers in science (Straw and Macleod, 2015). These findings are supported by the work of Mujtaba et al. (2015) who showed that simply emphasising the relevance and utility of science and explaining the type of work that scientists do has helped to increase students' interest and attainment in science. There is a dearth in the literature on the use of STEM Ambassadors in mathematics education, which this study aims to address.

This paper reports on a study conducted in Ireland to investigate the extent to which the relevance and utility of mathematics within careers are promoted by teachers and how well they are supported to do so, in terms of the resources that are available to them. There are many factors that could potentially influence how students perceive a subject such as parental or peer influence, cultural background, teacher influence etc. This manuscript argues that the use of real-life / applied mathematics, that is particularly focused on actual careers, is a powerful motivational tool that could be used to support and encourage students within mathematics. This study began by exploring the occurrence of career information in the textbook, as the textbook is the resource most commonly used by teachers within Irish classrooms (O'Sullivan, 2017). We endeavoured to investigate if, and how well, the most commonly used mathematics textbooks succeed in exemplifying the key role that mathematics plays in a variety of careers. This analysis demonstrated a clear paucity of career references in the textbooks examined. These findings motivated further inquiry. We wanted to investigate if teachers use the relevance and utility of mathematics as motivation for their students and, in the absence of an abundance of textbook examples, what resources they use as a supplement. Interviews conducted with a panel of seven teachers provided evidence that teachers are very much lacking in training and resources in this area, with the result being that the relevance and utility of mathematics in a range of careers is rarely highlighted. What resulted from these findings was the creation and dissemination of a teaching and learning package to fill this gap in resources and support secondary school mathematics teachers without adding to their workload. The package was designed to support teachers in convincing students that a knowledge of mathematics is crucial for the pursuit and execution of all careers, and to highlight that the mathematics they are studying at school is relevant to their futures.

\section{MATHEMATICS EDUCATION IN IRELAND}

In Ireland after eight years of primary school, students proceed to five or six years of secondary school. The Junior Cycle encompasses the first three years, culminating in the Junior Certificate examination (taken at approximately 16 years of age). This is followed by a two- or three-year senior cycle (many, but not all, students participate in an additional, non-academic year in the fourth year, called Transition Year) which concludes with the Leaving Certificate examination. Students typically study seven subjects for the Leaving Certificate and almost all students study mathematics. A fail in mathematics in the Leaving Certificate, means exclusion from many university degree programmes for those who intend on progressing directly there (there are alternative entry routes for adult learners returning to education after the age of 23). Mathematics can be taken at either Foundation, Ordinary or Higher level, the latter being the most demanding in terms of content quantity and rigour. Up until 2011 there was a steady decline in the numbers taking higher level mathematics at Leaving Certificate. At this time only 15.8\% of the school-leaving cohort chose to study mathematics at this level (State Examinations Commission, 2015). By 2019 participation rates had doubled to $32.9 \%$, mainly because of a bonus points incentive ${ }^{1}$ (Treacy, Prendergast

\footnotetext{
${ }^{1}$ The best six grades in the Leaving Certificate examination are counted towards a student's 'points'. A student's points score dictates entry to degree programmes at university. The maximum points a student can be awarded is 625 points, if they attain six H1 grades at higher level ( $6 \times 100$ points) plus an additional 25 'bonus points' if they achieve upwards of $40 \%$ in the higher-level mathematics examination. Bonus points are not awarded for any other subject.
} 
and O'Meara, 2019). While the increase in participation at Leaving Certificate higher level mathematics is welcomed, there is still a large cohort of students, $50 \%$ of those who take higher level mathematics in the Junior Certificate examination, who do not continue to study mathematics at higher level for senior cycle and opt to take ordinary level mathematics instead. Given the association between perceived relevance and uptake of advanced mathematics discussed earlier, we felt an initiative focussing on enhancing students' appreciation of mathematics might reduce this figure of $50 \%$.

State examinations that take place at the end of both the Junior and Senior Cycle place substantial pressure on both students and teachers with many teachers believing that the time allocated to mathematics during both cycles is insufficient (O’Meara and Prendergast, 2019; Prendergast and O'Meara, 2017). As such, any innovative intervention which researchers wish to pilot with post-primary students tends to take place in the optional year, Transition Year (also known as TY or 4th year). The philosophy of this non-academic 'gap' year is to promote students' social and personal development and it is recommended that schools and teachers should focus on increasing student engagement with mathematics and building confidence in students' mathematical abilities during TY (Clerkin, 2012). Furthermore, during this year mathematics teachers should introduce students to how mathematics pervades careers and inform them about the mathematics requirements and content of a variety of third-level courses (Moran, Perkins, Cosgrove and Shiels, 2013).

\section{METHODOLOGY}

\section{Overview}

This study was conducted in three phases. Phase one was an exploratory phase to quantify the extent to which textbooks in Ireland demonstrate the relevance and utility of mathematics across a range of careers. Phase two was a follow-on investigation to explore the extent to which teachers educate their students on the relevance and utility of mathematics and the resources they use in this effort, in the absence of supportive textbooks. This was done via semi-structured interviews with a panel of experienced mathematics teachers. Phase three was the development of an authentic, useful and novel suite of resources which is called Career Mathways, to fill the gaps previously identified in Phases one and two of the study. Phases one and two are detailed in the following sections.

\section{Phase One - Textbook analysis}

The predominant classroom aid used at secondary level in Ireland is the textbook (National Council for Curriculum and Assessment, 2005; O'Sullivan, 2017). Research shows that it has a significant influence on the teaching and learning that occurs in a classroom (Nathan, Long and Alibali, 2002). School mathematics textbook analysis is driven usually by concerns about the quality, suitability, presentation and inclusion (or lack thereof) of content (Petersson, Sayers, Rosenqvist and Andrews, 2020). Sometimes textbook analysis is a systematic comparison of local textbooks with texts from countries that are viewed as superior in terms of educational accomplishments (Petersson et al., 2020). As part of this study an analysis of the three most popular textbook series used in Transition Year and Senior Cycle in Ireland was conducted to see how frequently these textbooks highlighted the use of mathematics in careers. Our method of textbook analysis was a more rudimentary method of that used by Borba and Silva (2013) and Ding (2016). Borba and Silva (2013) analysed 48 textbooks in use in Brazil, to investigate how well they include and promote the use of calculators. They did this by identifying the instances of calculator usage and activities with calculators within the textbooks. Four distinct categories of activities were established, and all activities were subsequently categorised accordingly by independent researchers. The frequency and distribution of the activities were then recorded. Ding (2016) used a similar method in a study conducted on Chinese and US textbooks. Instances of addition and multiplication were coded, recorded and counted for each textbook analysed. Similarly, this method of textbook analysis was further supported by the work of Brating, Madej and Hemmi (2019) who analysed algebraic development in textbooks in Sweden, by counting the total number of pages devoted to the topic. Petersson et al. (2020, p. 209) state:

\footnotetext{
"Methodologically, much textbook-related research has employed some form of qualitative description, typically aligned with some form of analytical framework that may be supplemented by frequency analyses, whereby the number of occurrences of particular forms of task is counted and compared".
}

Our textbook analysis categorised two types of reference to careers: type (a), where a career is mentioned in the absence of any mathematical context e.g., 'a hairdresser goes on holiday to Spain every year', and type (b), where a career is mentioned within a mathematical context e.g., 'an accountant forecasts the projections for sales over a six-month period'. In order to carry out this analysis the research team first met and reviewed one chapter from one of the textbook series as a team in order to clarify the two different reference types and to determine how they 
would record the references. Each member of the team was then assigned one of the three most popular textbook series used in Senior Cycle in Ireland and they were required to identify all references to careers (type (a) and type (b) references) in the text, in the worked examples and in the problems posed for students. Upon completion of this task, and in order to ensure reliability, each of the researchers analysed a chapter from a different textbook series and compared their findings with those of the original reviewer. The results from this process indicated a very strong correlation between the two sets of analysis across all textbook series.

\section{Phase Two - Teacher Interviews}

Upon completion of the textbook analysis schools were randomly selected for participation in Phase 2. Initially six schools expressed an interest in participating thus guaranteeing a good geographical spread. Once schools were finalised semi-structured interviews were conducted with seven teachers from the different schools to ascertain the extent to which they demonstrate the relevance of mathematics within careers to their students and the resources/training available to support this endeavour. The questions contained in the interview broached teachers' perceptions of their own levels of knowledge in relation to the usefulness and applicability of mathematics. The interviews also sought to determine if teachers taught the relevance and utility of mathematics within careers to motivate their students in mathematics class, how they felt the textbooks supported them in this quest, what other resources were available and used by them and if they felt they have had adequate training to prepare them to deliver this level of information. Grounded theory was the method of analysis deemed most appropriate given the qualitative data collected in this phase of the study. What emerged from the analysis of textbooks and interview data is described next.

\section{RESULTS}

\section{Phase 1}

The results of the textbook analysis are summarised in Table 1.

Table 1. References to careers in three Irish textbook series

\begin{tabular}{|c|c|c|c|c|}
\hline & $\begin{array}{c}\text { Books in } \\
\text { Series }\end{array}$ & Descriptive Text & Worked Examples & Exercises \\
\hline & & 567.85 pages & $\mathrm{N}=1586$ & $\mathrm{~N}=3114$ \\
\hline Series A & 4 & $\begin{array}{l}6 \text { references to careers } \\
(4 \text { type (a), } 2 \text { type (b)) }\end{array}$ & $\begin{array}{l}44(2.77 \%) \text { references } \\
(25 \text { type (a), } 19 \text { type (b)) }\end{array}$ & $\begin{array}{l}103(3.31 \%) \text { references } \\
\text { (40 type (a), } 63 \text { type (b)) }\end{array}$ \\
\hline & & 279.35 pages & $\mathrm{N}=874$ & $\mathrm{~N}=4884$ \\
\hline Series B & 3 & $\begin{array}{l}100 \text { references to careers } \\
(49 \text { type (a), } 51 \text { type (b)) }\end{array}$ & $\begin{array}{l}25(2.86 \%) \text { references } \\
(12 \text { type (a), } 13 \text { type (b)) }\end{array}$ & $\begin{array}{l}155(3.17 \%) \text { references } \\
(80 \text { type (a), } 75 \text { type (b)) }\end{array}$ \\
\hline Series C & 3 & $\begin{array}{l}374.12 \text { pages } \\
10 \text { references to careers } \\
(2 \text { type }(a), 8 \text { type }(b))\end{array}$ & $\begin{array}{l}\mathrm{N}=685 \\
9(1.31 \%) \text { references } \\
(1 \text { type (a), } 8 \text { type (b)) }\end{array}$ & $\begin{array}{l}\mathrm{N}=5103 \\
77(1.51 \%) \text { references } \\
(25 \text { type (a) }, 52 \text { type (b)) }\end{array}$ \\
\hline
\end{tabular}

From Table 1 we can see that out of a total of 3,145 worked examples across the three series of books, only $1.28 \%$ utilised a career focus (type (b)) in a mathematics context in the examples. $1.2 \%$ of the examples mentioned careers in the absence of any mathematics context (type (a) references). There were 13,101 exercises across the three series of textbooks and only $190(1.45 \%)$ of these used a career within a mathematics context as motivation within the question. $1.11 \%$ of the exercises had a type (a) reference. The three textbook series collectively contained approximately 1221.32 pages of descriptive text (we gauged incomplete pages of text to be $\frac{\mathbf{1}}{\mathbf{3}}, \frac{\mathbf{1}}{\mathbf{4}}, \frac{\mathbf{1}}{\mathbf{5}} \mathrm{etc}$. full of text, then summed them). Within these pages, we found a total of 116 references to careers, but only 61 of these were instances where the career was mentioned in a mathematics context.

It is worth noting that we are not suggesting that relevance is solely an issue within mathematics, nor are we implying that it is worse in mathematics textbooks than in other subjects. Teppo and Rannikmäe (2003) and Sjøberg and Schreiner (2015) have highlighted relevance as an issue within science education. Sjøberg and Schreiner (2015) in particular criticized textbooks in Norway for their lack of emphasis on relevance but a textbook analysis to identify percentage cover was not conducted. Osborne and Collins (2001) reported on the issues of relevance in chemistry education, where secondary school students failed to see how it related to their everyday lives or their futures. The study was conducted with a large number of focus groups consisting of secondary school students. It did not refer to how well relevance was addressed within chemistry textbooks, however. So, while relevance is also clearly an issue for other STEM subjects, the reality is that mathematics has more applications across other subject 
areas than other STEM disciplines so applications based on realistic scenarios should form a core part of any mathematics education (Ubuz, Gravemeijer, Stephan and Capraro).

\section{Phase 2}

One of the main findings from the interviews conducted with teachers for this study was that the majority of secondary school students do not see the relevance of mathematics. As part of the second phase of this study the teachers were asked if their students appreciate the usefulness of mathematics in their lives. Two teachers stated that students acknowledge its importance because of its core status on the syllabus and its role as a gatekeeper into university. Teacher 1 said

"I don't know if they appreciate how much they will use it, but I think they, it's more that they know they have to have it".

Teacher 7 said that students have an awareness it is an important subject because their parents tell them it is,

"Some of them do [appreciate how important mathematics is]. It's definitely emphasized at home".

However, six of the seven teachers stated that students have a negative view of mathematics and do not see its relevance to real life. As Teacher 2 stated,

"If you're teaching algebra there is always a lot of 'when am I going to use this in real life?'... I think in general there is such a negative vibe around it [mathematics]"

Teachers 4 and 1 stated that the negative perception stems from the fact that they are not informed about the relevance of the mathematics they study at school.

T4: '..and some of them kind of don't really understand that you do need it in everyday life. And maybe that's to do with the syllabus. The syllabus is a bit detached from, em, everyday life'.

T1: "I think a lot of the time it's probably difficult for them to see where they'd use probability or where they'd use algebra, or where they'd use trigonometry or anything like that so it's probably that they just don't really see where it is applicable in their later on life".

In the process of the interview, teachers were also asked to provide their opinions in relation to how useful they believed the textbook was in highlighting the relevance and applicability of mathematics. They informed us that while the textbooks available make an attempt to introduce applications of concepts, they do not highlight the relevance of mathematics within careers. All seven teachers stated that the textbooks they use are inadequate for this purpose. When asked if the textbooks they use demonstrate the importance of mathematics in the real world, Teacher 1 told us

"Probably not very well to be honest. [The textbook is] more geared towards the exam really...I think myself they're not really imparting how useful [mathematics] is".

Teacher 7 was more forceful in his reply saying the textbooks are 'borrific' for this purpose.

When asked if there were resources available to help them convey how important mathematics is within a range of careers, six out of the seven teachers stated that there is a distinct lack of resources available to help them educate students in this area. Teacher 5 highlighted how in their search for resources they have

“..never come across anything talking about careers. The odd things, very basic stuff, but nothing in any way in detail or really informative."

These sentiments were reiterated by the other teachers, including Teacher 2, who felt that there was a dearth of resources available regarding the role of mathematics in careers and that this hindered their ability to communicate the pervasiveness of mathematics within careers to their students, "Definitely not [a lot of resources] I would say. I would say there is very, very little".

Four of the seven teachers said there are resources available on the internet, but it is very time-consuming searching for something appropriate. Teacher 7 said that "There's incredible stuff out there more than ever. Em, the problem nowadays is there's too much". Teacher 1 echoed these sentiments that there are resources available, but it can take quite some time to find what you need,

"There's loads of stuff in kind of TED [Technology, Entertainment, Design] and those kind of things but again you could spend an hour trying to find something". 
Two teachers said however, that some resources do not always translate easily for use in an Irish context. Teachers 2 gives a good example of this:

"I came across a thing and it was actually really good and it was American and it was just kinda like how, it was kinda like maths for everyday life and there was a unit on measurement and converting, like there was a picture of weighing scales and those kinda things, and it was really basic and there was an example of how you had to budget for your holiday and those kind of things, but again all the units were off because it was American and it didn't really translate."

Typically, teachers do not use careers to motivate students in mathematics. Five of the seven teachers said they never use careers as a way of motivating students in mathematics class. Teacher 5 said "T use different resources to engage them with maths but not in relation to careers." One teacher said she tried to but only 'the obvious' jobs where mathematics plays a key role. Another said she informs students they will need mathematics in their futures whatever path they choose but does not give specific mathematical examples of this.

T1: "Probably not as much as I should. I feel comfortable doing the maths that we're doing if you know what I mean but probably imparting, em, where they would see where it would be useful to them in their later life is something that I, I'd like to improve in my teaching because at the minute it's just, it's a matter of can you do that and then move onto the next thing".

The teachers were asked if they felt that they had had sufficient preparation or support thus far in their careers to educate their students about the utility of mathematics within careers. What emerged was that, in general, these teachers feel they have not been adequately educated or supported to do so either in their teacher education or via CPD events. Five out of the seven teachers interviewed in this study said that training in this has area for them had been limited and left them feeling underprepared to teach specific examples of the relevance of mathematics in a range of careers. Only two teachers said they felt adequately prepared to integrate this into their teaching. One who has 23 years of teaching experience said it is up to individuals themselves if they wish to upskill. The remaining teacher interviewed had worked in a career in finance before training as a teacher and had witnessed the importance of mathematics first-hand and was able to relay this to their students when needed. Teachers 3 and 4 stated respectively; "No. I think the training is ... I suppose lacking", and "Training bas] been limited". Teacher 5 said she feels 'extremely inadequate' in the knowledge required to teach the relevance of mathematics within a range of careers.

The final finding to emerge from these interviews with the teachers was the heavy emphasis on examinations in Ireland. This was mentioned by six of the seven teachers as being detrimental to teaching anything off-syllabus. Teachers of examination groups are reluctant to spend time on something that is unlikely to be formally examined.

The analysis conducted on the most commonly used local textbooks in Ireland provided evidence that the relevance and utility of mathematics within most occupations is all but absent in the text and exercises that students and teachers work with on a daily basis. Interviews with experienced teachers confirmed these findings, and further informed us that resources that demonstrate the relevance of mathematics are difficult and time-consuming to find and training in this area for mathematics teachers is inadequate. The cumulative results of this work confirm suspicions that issues of relevance in mathematics apparent in other countries as outlined in the literature earlier are prevalent in Ireland too. These research findings inspired an intervention entitled Career Mathways, a medium through which teachers can inform students about the relevance and utility of mathematics in a range of career pathways that are not explicitly mathematical.

\section{Phase 3 - The Inception of Career Mathways}

To address the shortcomings highlighted in the textbook analysis, and the feedback from the teachers, the research team conceptualised an initiative entitled 'Career Mathways'. This initiative involved collaboration with several high-profile Irish personalities and professionals by inviting them to become STEM Ambassadors, with the overall aim of helping to make STEM, and mathematics in particular, more visible and relevant to students. A variety of professionals were approached: a chef, a florist, a farmer, a garda (Irish police officer) vehicle collision expert, a hairdresser, a veterinary nurse, a doctor, a dentist, a sports scientist, a photographer, a lawyer, a radio presenter, a sports presenter, and a meteorologist. More typical mathematics intensive careers, for example those in engineering or science, were avoided and instead careers where the relevance and need for mathematics was not so explicit were chosen. Fourteen professionals agreed to act as STEM Ambassadors and consented to be interviewed and video recorded by the research team.

When the interviews with the STEM Ambassadors were completed, we developed a teaching and learning package based on the mathematical content contained in the interviews. This package consisted of: 12 six-minute professionally produced video clips of the STEM Ambassadors detailing their careers and the mathematics that underpins them, a series of 12 posters that contained still images of the STEM Ambassadors and a quote of theirs 


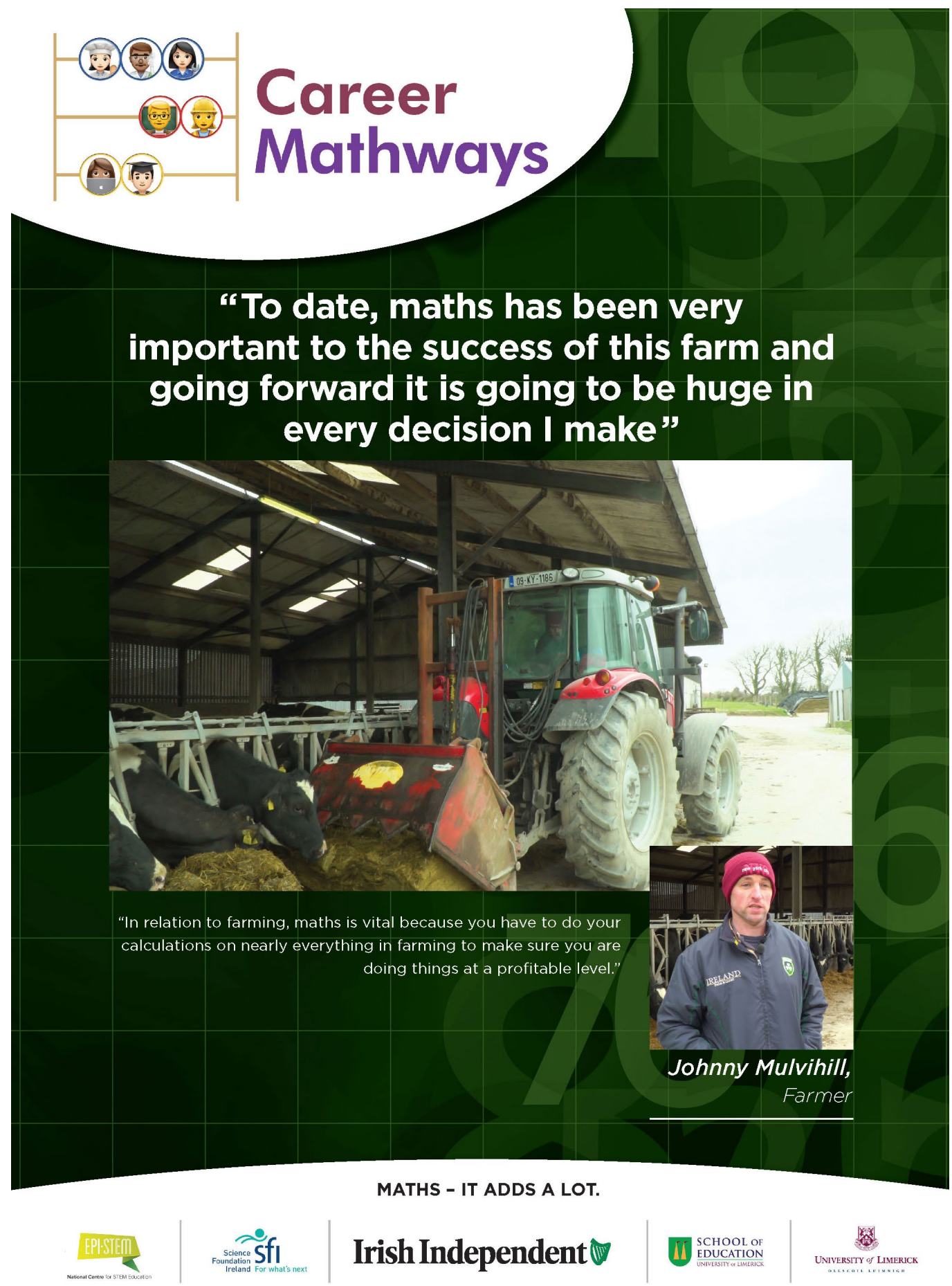

Figure 1. Poster from Farmer Interview

emphasising how mathematics plays a key role in their careers (see Figure 1) and a teacher handbook comprising 36 teaching and learning guides/plans (3 based on each occupation) with accompanying PowerPoint presentations for each lesson. A student handbook that comprised 36 worksheets, which aligned with the teaching and learning guides, was also created.

In a bid to ensure authenticity of content, all material contained in the teaching and learning resources were based on real and/or realistic tasks undertaken by the STEM Ambassadors in their daily lives and careers that require a level of mathematical skills and knowledge. For example, the farmer discussed grass growth on his farm and this example was used to teach students about arithmetic sequences (see Figure 2). We also outlined explicitly where the content in each teaching and learning guide was aligned with content in the school curriculum to demonstrate to students how relevant the content was to the real world and careers they might potentially consider when they finish school. We acknowledge that the real/realistic applications used to create these resources may not be relevant to students' lives at present, but their purpose is to illustrate that whatever career they ultimately choose, the need for a good foundation in mathematics is crucial. 


\section{Activity 1}

Farmer - Lesson 2

Johnny is preparing a field for grazing. On the beginning of day 1 the grass is $2 \mathrm{~cm}$ high. Due

to a spell of good weather, the grass is expected to grow at a rate of $0.5 \mathrm{~cm}$ a day.

a) Complete the table below to show the height of the grass at the beginning of each day of the coming week.

\begin{tabular}{|c|c|c|c|c|c|c|c|}
\hline Day & 1 & 2 & 3 & 4 & 5 & 6 & 7 \\
\hline Height & & & & & & & \\
\hline
\end{tabular}

b) Use the grid below to represent the growth of grass from part (a) graphically.

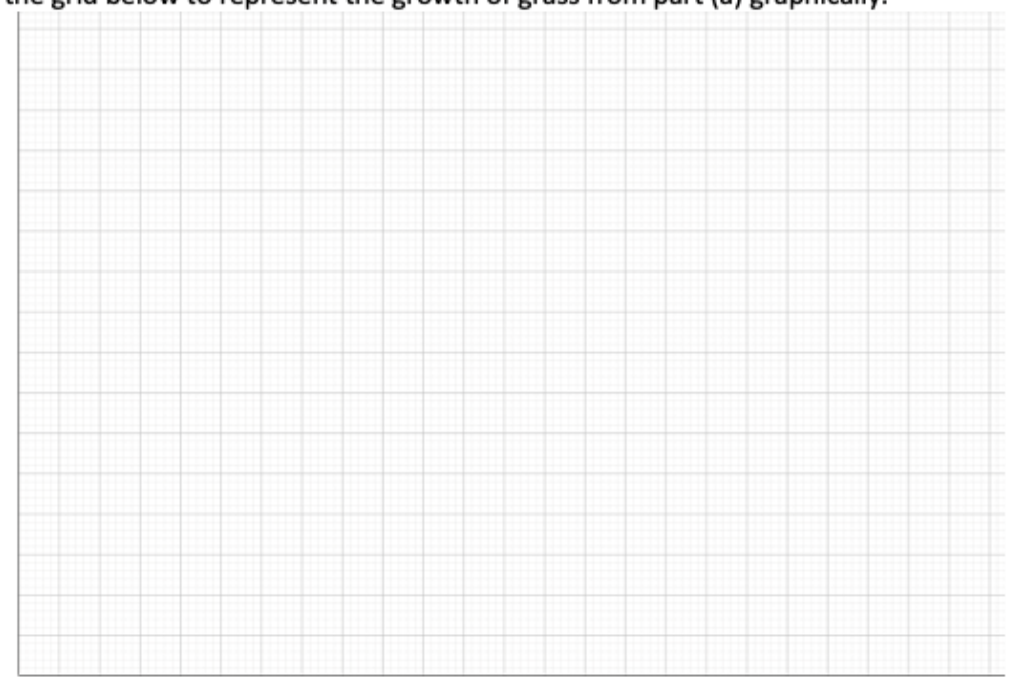

Figure 2. Excerpt from a student worksheet based on the farming interview which formed the basis for the teaching of arithmetic sequences

Initially, eight schools were approached, and their TY teachers were invited to take part in the Career Mathways initiative, but ultimately only five secondary schools (184 students) participated in this pilot study. The teachers were invited to attend an induction evening in the researchers' university where they were provided with all the resources created for the Career Mathways initiative. They were given 12 weeks to implement the initiative with their TY classes. There was enough flexibility within the project to allow teachers to select which careers or mathematical topics they wanted to focus on. The research team remained in regular contact with the participating teachers throughout its implementation. The focus of this stage of the project was not on professional development, but on piloting the initiative and seeing how the teachers and students implemented the teaching and learning package. There was, however, a two-hour induction to introduce the range of resources to the teachers and discuss the possible ways in which it could be utilised in the classroom. The intervention itself and its evaluation will be detailed in another paper.

\section{CONCLUSIONS AND RECOMMENDATIONS}

The capacity of secondary school students to appreciate the relevance and utility of mathematics in future study and careers is a problematic issue in mathematics education. One of the key factors that influences a student's subject choice is their perception of how useful the subject will be for further study and for career purposes (Bennett et al., 2014; Johnston, 1994; Jones, 1988; Matthews and Pepper, 2006; Mujtaba et al., 2018; Sheldrake et al., 2015; Tripney et al., 2010). Research shows however that students do not see the relevance of the mathematics they study at school to their future (Brown et al., 2008; Kyriacou and Goulding, 2006) or the real world (Quilter and Harper, 1988). The teachers interviewed in this study also confirmed this to be the case in Ireland.

Brown et al. (2008) recommend that the usefulness of mathematics be communicated through the curriculum in the classroom. Freudenthal believed that mathematics education should be designed and delivered in a way that will facilitate the solving of problems in everyday-life situations, as that is the capacity in which the majority of those who study mathematics will require it (Gravemeijer and Terwel, 2000). Embedding real-world contexts within mathematics has the potential to highlight its relevance to both students and teachers, and can act as a 
vehicle to boost motivation, interest and achievement (Honey, Pearson and Schweingruber, 2014; Hoogland, de Koning, Bakker, Pepin and Gravemeijer, 2018; Laurens et al., 2017). Furthermore, the move from real-life to the abstract (horizontal and vertical mathematising), as emphasised in RME, is critical for students to progress in the discourse of mathematics, and thus was selected as the framework for the intervention described in this study.

Careers education needs to help broaden students' awareness of the value of mathematics qualifications and the wide range of further study and career opportunities they open up (Archer et al., 2013). Archer et al. (2013) endorse embedded models of careers education, where teaching and learning is purposefully linked to various careers as much as possible. Embedded STEM careers education entails teachers of STEM using materials and pedagogic practices to communicate how STEM subjects are used in the world of work (Reiss and Mujtaba, 2017). It has been shown that interventions of this nature are effective in nurturing engagement. Effective careers education provision must incorporate the creation of a range of teaching and learning resources, alongside appropriate Continuing Professional Development (CPD) (Bennett et al., 2014). However, successful implementation of effective careers education into the curriculum of schools will not happen without appropriate support for teachers in place (Archer et al., 2013). It is difficult for teachers of any subject to combine enrichment activities with their teaching duties in an already crowded curriculum (Smart and Rahman, 2008). The teachers interviewed in this study stated the textbooks used in their classrooms do not fulfil this purpose and while there may be resources available on the internet, it can be very time-consuming to find ones appropriate for their students. Career Mathways is a suite of teaching and learning resources that offers a potential solution to issues of relevance and embedded careers education where teachers are already overburdened as it marries careers education with mathematics content on the school syllabus. It is one way of addressing the issue of the relevance of mathematics alongside the limited resources, and time, available to secondary school teachers to impart this in a realistic and effective way. In addition to CPD for inservice teachers, careers education for preservice teachers in Initial Teacher Education is also worth exploring. The researchers in this study who are all mathematics teacher educators have already started to embed the relevance of mathematics in careers within mathematics pedagogy modules in their institution. In this way, future teachers of mathematics are informed on this topic before they even qualify.

In this paper we provide an explanatory account of the exigency and design of an educational intervention to improve the knowledge of secondary school teachers and students of the relevance and utility of mathematics within a range of careers. In developing this intervention, we drew on a range of evidence including: literature from other countries where relevance has been an issue in mathematics education, an analysis of textbooks in Ireland, and interviews with experienced teachers. We conclude the description of this pilot study with three main recommendations for the future of Career Mathways. Firstly, we recognise the need for a comprehensive evaluation of the programme. The development of a valid research instrument to measure the impact of Career Mathways on student knowledge and engagement with mathematics needs to be created and administered, to provide empirical evidence that the intervention is a success. Secondly, arising from the evidence attained from the teachers interviewed in this study the creation of a professional development programme to prepare and support teachers who wish to embed the Career Mathways initiative (or any similar initiative) in their classrooms is necessary. This will ensure the programme is implemented appropriately in a manner that informs and supports the enhancement of students' knowledge regarding the relevance and utility of mathematics. Finally, research indicates that issues of relevance and utility are not solely the concern of mathematics and are contributing factors to poor participation rates in other STEM subjects (Archer et al., 2013). It has been shown that many young people and their families have a very superficial understanding of how STEM plays a part in scientific and non-scientific careers (Bennett et al., 2014). We believe that Career Mathways is an initiative that can easily be extended to these disciplines, where engagement and participation levels need enrichment.

\section{REFERENCES}

Archer, L., Osborne, J., De Witt, J., Willis, B. and Wong, B. (2013). The ASPIRES Project (Children's science and careers' aspiration, age 10-14). Interim research report summary. Available at: https://www.kcl.ac.uk/ecs/research/aspires/ aspires-final-report-december-2013.pdf

Bennett, J., Braund, M. and Sharpe, R. (2014). Student attitudes, engagement and participation in STEM subjects. Project report. London: The Royal Society/Department of Education, The University of York. Available at: http:/ / eprints.lincoln.ac.uk/id/eprint/14666/1/ev-3-vision-research-reports-20140624.pdf

Borba, R. and Selva, A. (2013). Analysis of the role of the calculator in Brazilian textbooks. ZDM - International Journal on Mathematics Education, 45(5), 737-750. https://doi.org/10.1007/s11858-013-0517-3

Bråting, K., Madej, L. and Hemmi, K. (2019). Development of algebraic thinking: opportunities offered by the Swedish curriculum and elementary mathematics textbooks. Nordisk matematikkdidaktikk, NOMAD:[Nordic Studies in Mathematics Education], 24(1), 27-49. 
Brown, M., Brown, P. and Bibby, T. (2008). "I would rather die": Reasons given by 16-year-olds for not continuing their study of mathematics. Research in Mathematics Education, 10(03), 3-18. https://doi.org/10.1080/ 14794800801915814

Central Applications Office. (2020). CAO Handbook 2020. Available at: http://www2.cao.ie/handbook/ handbook2020/hb.pdf

Clerkin, A. (2012). Personal development in secondary education: The Irish Transition Year. Education Policy Analysis Archives, 20(38). https:// doi.org/10.14507/epaa.v20n38.2012

Devrim, U. and Uyangor, S. M. (2006). Attitudes of 7th class students toward mathematics in realistic mathematics education. International Mathematical Forum, 1(39), 1951-1959. https:/ / doi.org/10.12988/imf.2006.06172

Expert Group on Future Skills Needs. (2008). Statement on raising national mathematical achievement. Dublin: EGFSN.

Flegg, J., Mallet, D. and Lupton, M. (2012). Students' perceptions of the relevance of mathematics in engineering. International Joumal of Mathematical Education in Science and Technology, 43(6), 717-732. https:// doi.org/10.1080/0020739X.2011.644333

Freudenthal, H. (1968). Why to teach mathematics so as to be useful. Educational Studies in Mathematics, 1(1), 3-8. https:// doi.org/10.1007/BF00426224

Freudenthal, H. (1991). Revisiting Mathematics Education: China Lectures. Dordrecht: Kluwer Academic.

Gill, O. (2006). What Counts as Service Mathematics?: An Investigation Into the 'Mathematics Problem' in Ireland. (Unpublished doctoral thesis), University of Limerick, Ireland.

Gravemeijer, K. and Terwel, J. (2000). Hans Freudenthal: a mathematician on didactics and curriculum theory. Journal of curriculum studies, 32(6), 777-796. https:// doi.org/10.1080/00220270050167170

Hodgen, J. and Askew, M. (2007). Emotion, identity and teacher learning: Becoming a primary mathematics teacher. Oxford Review of Education, 33(4), 469-487. https:/ / doi.org/10.1080/03054980701451090

Honey, M., Pearson, G. and Schweingruber, H. A. (2014). STEM integration in K-12 education: Status, prospects, and an agenda for research (Vol. 500). Washington, DC: National Academies Press.

Hoogland, K., de Koning, J., Bakker, A., Pepin, B. E. U. and Gravemeijer, K. (2018). Changing representation in contextual mathematical problems from descriptive to depictive: The effect on students' performance. Studies in Educational Evaluation, 58, 122-131. https:// doi.org/10.1016/j.stueduc.2018.06.004

Hoyles, C., Wolf, A., Molyneux-Hodgson, S. and Kent, P. (2002). Mathematical Skills in the Workplace Final Report to the Science, Technology and Mathematics Council. London: University of London and Science, Technology and Mathematics Council.

Hulleman, C. S. and Harackiewicz, J. M. (2009). Promoting interest and performance in high school science classes. Science, 326(5958), 1410-1412. https://doi.org/10.1126/science.1177067

Irish Business and Employers Confederation (2018). Informed choices: career guidance in an uncertain world. Available at: https:/ /www.ibec.ie/employer-hub/informed-choices-career-guidance-in-an-uncertain-world

Johnston, S. (1994). Choosing mathematics. 'You need it even if you don't want to do it'. Australian Journal of Education, 38(3), 233-249. https://doi.org/10.1177/000494419403800304

Jones, W. (1988). Secondary school mathematics and technological careers. Hawthorn: Australian Council for Educational Research.

Keogh, J., J, Maguire, T. and O'Donoghue, J. (2018). Adults, mathematics and work: from research into practice. Leiden: Brill Sense. https://doi.org/10.1163/9789004381766

Kyriacou, C. and Goulding, M. (2006). A systematic review of strategies to raise pupils' motivational effort in Key Stage 4 Mathematics. London: EPPI-Centre, Social Research Unit, Institute of Education.

Laurens, T., Batlolona, F. A., Batlolona, J. R. and Leasa, M. (2017). How does realistic mathematics education (RME) improve students' mathematics cognitive achievement? Eurasia Journal of Mathematics, Science and Technology Education, 14(2), 569-578. https://doi.org/10.12973/ ejmste/76959

Matthews, A. and Pepper, D. (2006). Evaluation of participation in A-level mathematics. Interim report. London: Qualifications and Curriculum Agency.

Moran, G., Perkins, R., Cosgrove, J. and Shiels, G. (2013). Mathematics in Transition Year: insights of teachers from PISA 2012. Dublin: Educational Research Centre.

Mujtaba, T., Reiss, M. J. and Hodgson, A. (2014). Motivating and supporting young people to study mathematics: A London perspective. London Review of Education, 12(1), 121-142. https://doi.org/10.18546/LRE.12.1.11

Mujtaba, T., Reiss, M. J., Rodd, M. and Simon, S. (2015). Methodological issues in mathematics education research when exploring issues around participation and engagement. In J.A. Middleton, J. Cai and S. Hwang (Eds.), Large-Scale Studies in Mathematics Education (pp. 335-362). Cham: Springer. https://doi.org/10.1007/978-3-31907716-1_15

Mujtaba, T., Sheldrake, R., Reiss, M. J. and Simon, S. (2018). Students' science attitudes, beliefs, and context: associations with science and chemistry aspirations. International Journal of Science Education, 40(6), 644-667. https://doi.org/10.1080/09500693.2018.1433896 
Nardi, E. and Steward, S. (2003). Is mathematics T.I.R.E.D? A profile of quiet disaffection in the secondary mathematics classroom. British Educational Research Journal, 29(3), 345-367. https://doi.org/10.1080/01411920301852

Nathan, M. J., Long, S. D. and Alibali, M. W. (2002). The Symbol Precedence View of Mathematical Development: A Corpus Analysis of the Rhetorical Structure of Textbooks. Discourse Processes, 33(1), 1-21. https://doi.org/10.1207/S15326950DP3301_01

National Council for Curriculum and Assessment. (2005). Review of mathematics in post-primary education: a discussion paper. Dublin: NCCA.

O’Meara, N. and Prendergast, M. (2019). Teaching mathematics after hours. Journal of Curriculum Studies, 51(4), 494512. https://doi.org/10.1080/00220272.2018.1535666

O'Sullivan, B. (2017). An analysis of mathematical tasks used at second-level in Ireland. (Unpublished doctoral thesis), Dublin City University, Ireland.

Osborne, J. and Collins, S. (2001). Pupils' views of the role and value of the science curriculum: a focus-group study. International Journal of Science Education, 23(5), 441-467. https://doi.org/10.1080/09500690010006518

Petersson, J., Sayers, J., Rosenqvist, E. and Andrews, P. (2020). Two novel approaches to the content analysis of school mathematics textbooks. International Journal of Research \& Method in Education, 1-15.

Prendergast, M. and O'Meara, N. (2017). A profile of mathematics instruction time in Irish second level schools. Irish Educational Studies, 36(2), 133-150. https:/ / doi.org/10.1080/03323315.2016.1229209

Quilter, D. and Harper, E. (1988). 'Why we didn't like mathematics, and why we can't do it'. Educational Research, 30(2), 121-134. https:// doi.org/10.1080/0013188880300206

Reiss, M. J. (2004). Students' attitudes towards science: A long-term perspective. Canadian Journal of Science, Mathematics and Technology Education, 4(1), 97-109. https://doi.org/10.1080/14926150409556599

Reiss, M. J. and Mujtaba, T. (2017). Should we embed careers education in STEM lessons? Curriculum Journal, 28(1), 137-150. https://doi.org/10.1080/09585176.2016.1261718

Sheldrake, R., Mujtaba, T. and Reiss, M. J. (2015). Students' intentions to study non-compulsory mathematics: The importance of how good you think you are. British Educational Research Journal, 41(3), 462-488. https://doi.org/10.1002/berj.3150

Sjøberg, S. and Schreiner, C. (2005). How do learners in different cultures relate to science and technology? Results and perspectives from the project ROSE (the Relevance of Science Education). Asia-Pacific Forum on Science Learning and Teaching, 6(2).

Smart, S. and Rahman, J. (2008). Bangladeshi girls choosing science, technology, engineering and maths. An exploration of factors that affect Bangladeshi girls' achievement in, engagement with and aspirations in STEM subject areas. London: Institute for Policy Studies in Education, London Metropolitan University.

Smith, A. (2004). Making mathematics count: The report of Professor Adrian Smith's inquiry into post-14 mathematics education. London: The Stationary Office.

State Examinations Commission (2015). Leaving Certificate examination 2015. Mathematics. Chief Examiner's report. Dublin: State Examinations Commission.

Straw, S. and Macleod, S. (2015). Evaluation of STEMNET's operations and impacts 2011-2015: Summary report. Slough: National Foundation for Educational Research.

Tebbutt, M. J. (1993). Sixth Formers' Perceptions of A Level and Degree Courses in Physics and Mathematics. Research in Science \& Technological Education, 11(1), 27-37. https:// doi.org/10.1080/0263514930110104

Teppo, M. and Rannikmäe, M. (2003). Increasing the relevance of science education - student preferences for different types of teaching scenarios. Journal of Baltic Science Education, 2(2), 49-61.

Treacy, P., Prendergast, M. and O’Meara, N. (2020). A “new normal”: Teachers' experiences of the day-to-day impact of incentivising the study of advanced mathematics. Research in Mathematics Education, 22(3), 233-248. https://doi.org/10.1080/14794802.2019.1668832

Treffers, A. (1993). Wiskobas and Freudenthal Realistic Mathematics Education. In L. Streefland (Ed.), The Legacy of Hans Freudenthal (pp. 89-108). Dordrecht: Springer Netherlands. https://doi.org/10.1007/978-94-017-33779_6

Tripney, J., Newman, M., Bangpan, M., Nisa, C., Mackintosh, M. and Sinclair, J. (2010). Factors influencing young people (aged 14-19) in education about STEM subject choices: A systematic review of the UK literature. London: Wellcome Trust.

Ubuz, B., Gravemeijer, K., Stephan, M. and Capraro, P. (2019). Introduction to TWG26: Mathematics in the context of STEM education. Available at: https:// hal.archives-ouvertes.fr/hal-02410294/document

Vos, P. (2020). Task contexts in Dutch mathematics education. In National Reflections on the Netherlands Didactics of Mathematics (pp. 31-53). Cham: Springer. https://doi.org/10.1007/978-3-030-33824-4_3 